\title{
Bioinformatics Curriculum: A Comparative Analysis in Pakistani Perspective
}

\author{
Anas Mohammad Jawarneh", ${ }^{1, *}$ Azhar Ali Shah ${ }^{2}$, Zain-UL-Abdin Khuhro ${ }^{3}$, Shahzad Ahmed Memon ${ }^{4}$ \\ ${ }^{1}$ Researcher of Information Technology, University of Sindh, Pakistan \\ ${ }^{2}$ Professor of Information Technology, University of Sindh, Pakistan \\ ${ }^{3}$ Institute of Mathematics and Computer Science, University of Sindh, Pakistan \\ ${ }^{4}$ Institute of Information and Communication Technology, University of Sindh, Pakistan
}

Copyright $\bigcirc 2017$ by authors, all rights reserved. Authors agree that this article remains permanently open access under the terms of the Creative Commons Attribution License 4.0 International License

\begin{abstract}
Bioinformatics has been a hot topic in Pakistan to be a separate and vital field of study. There has been a sudden increase in the Bioinformatics courses for both undergraduate and graduate degrees. The courses selected in this study four years bachelor degree and two year master degree of full-time study, each of these courses dissecting into six categories as: Bioinformatics, Biological Science, Mathematics, Statistics, Computer Science and Elective subjects, to determine where the differences lie. This study reviews state-of-the-art Bioinformatics education in Pakistan, compares it with global standards and initiatives and proposes a set of recommendations to be integrated in the national educational framework of curriculum and policy making.
\end{abstract}

Keywords Bioinformatics, Global Standards, Undergraduate, Educational Framework, Curriculum, Graduate

\section{Introduction}

Bioinformatics is the interdisciplinary science of using computers for the collection, processing, storage, retrieval, interpret and analyze biological data tremendous to solve biological problems; resulting from genome projects and high-throughput biological experiments. Computer systems play an important role to translate biological data into useful knowledge can be relied upon practical experiences and theories of teaching. Bioinformatics as a multidisciplinary field depend on knowledge of biology, computer science, mathematics, physics, and chemistry [1-2].

Bioinformatics focuses on two main flows of data in modern biology. The first depends on the flow of genetic information of the DNA, RNA and protein sequences, the second on the flow of information on the hypotheses [3-4]. This flow of the Bioinformatics information is considered a crucial portion of the curriculum, which would be a set of core Bioinformatics courses that build upon the contributing disciplines to present the basic intellectual structure of the field.

Recent articles have highlighted the dearth, in the academia of Bioinformatics and the need for programs that could address the sciences in the disparate fields, and immerse students in both theory and experimental aspects of Bioinformatics research to acquiring core competency in the biological and computer sciences [5-6]. These challenges have paved the way for projects for academic booming, providing opportunities and hypotheses for the introduction of experiments and applications to life through computer tools to speed up the production of massive amounts of data needed to understand the new technology [7]. Most disciplines have begun to adopt curriculum relevant to Bioinformatics and tools oriented towards information technology because of the high-performance computing, interoperability and portability of data, and compatibility on the internet [8-9].

This study reviews the Bioinformatics education in Pakistan with other countries and explains the components that constitute the Bioinformatics field, analyze the unique education criteria that are required to produce students with Bioinformatics training and provide an overview of global Bioinformatics education to further improve our implementation of Bioinformatics education.

\section{Related Work}

In the context of Pakistani perspective to develop Bioinformatics education and stepwise progress in it, Ilyas, highlights the rise of Bioinformatics in Pakistan and introduced Bioinformatics in 2003 in Pakistan [10], when Muhammad Ali Jinnah University and COMSATS Institute of Information Technology (CIIT) offered undergraduate program in this field. The Higher Education Commission (HEC) of Pakistan performs continual revision the 
curriculum in collaboration with universities. In 2006, the National Curriculum Review Committee (NCRC) defined a curriculum for the BS (4 years) and a Master degree in Bioinformatics for all public and private universities [11], and in 2010, the National Curriculum Review Committee (NCRC) of Bioinformatics revised the curriculum of Bioinformatics for BS (4-years) and MS (2-years) degree programs [12]. This initiative greatly strengthened the demand of new graduates in Pakistan, Where will be training new professionals and will be established Bioinformatics servers, which presented another market for local graduates.

While discussing on the question of a proper curriculum for Bioinformatics professional Russ B. Altman proposes two models [1]. The first model focuses on post-doctoral fellows having core training in a technical field of either computer science or in a sub-discipline of biology. They require specialty training in computational biology in order to become a 'computer scientist who specializes in biology' or a 'biologist who specializes in computer science'. In the second model, graduate students are trained in Bioinformatics or computational biology without a preliminary training in one of the contributing disciplines. The curriculum for these students must provide them with a set of skills which are long-lasting and endures beyond the current fads. This article argues that the idea of training undergraduates in Bioinformatics is quite intriguing. It proposes a framework for curriculum which is divided into five areas useful to the requirements of the course program in Bioinformatics. These areas include Biology, Computer Science, Statistics, Ethics and Core Bioinformatics.

Ragunath, Venkatesan \& Ravimohan, designed a curriculum model to follow three tier architecture models for the Bioinformatics graduate program using a systems biology approach [13]. The three tier architecture model is based on three layers. Each layer consists of a reusable piece of code that performs specific task, each capturing a different aspect of the information as given bellow:

- The data layer: A front-end 'Web Server' serving static content, and potentially some cached dynamic content.

- Business layer: A middle dynamic content processing and generation level of Application server, for example ASP.net, Java, PHP platform.

- $\quad$ Presentation layer: A back-end Database, comprising both data sets and the Database management system that manages and provides access to the data.

And he has classified these layers into three levels: (a) Basic Subjects, (b) Intermediate Subjects and (c) Advanced Subjects.

The proposed framework involves five tracks to classify a curriculum Bioinformatics in content. As:

1 Hardcore Bioinformatics Track, preferred by students with Biology background.

2 Drug Designers Track, preferred by students with Chemistry or Biophysics background.

3 Analyst Track, preferred by students with a strong background in Biostatistics and Biomathematics.

4 Information Technology (IT) Track, preferred by the students with IT background.

5 Research Track, This track is preferred by students opting for research positions.

Thus, the curriculum model which is designed for the graduate program in Bioinformatics addressed most of the issues related to the design of educational programs under each discipline to achieve these goals so that students are able to progress through their studies in an integrated manner. Searls identified a set of five possible tracks for Bioinformatics curriculum [7], these tracks indicated to courses in virtual departments which represent an assumed background for individuals entering the track.

1 Bioinformatics Analysis (BA): This track prepares students to analyze biological data in order to interpretation or prediction.

2 Data Mining (DM): This track provides more sophisticated analysis of data sets which are complex; it entails a greater depth of both mathematical knowledge and programming skills.

3 Bioinformatics Tools (BT): This track is interested to develop tools for Bioinformatics analysis, presentation, visualization, and local data management, it requires programming skills and algorithms and the ability to implement efficiently.

4 Bioinformatics Systems (BS): This track is one of the competencies of software engineering are able to develop main Bioinformatics systems.

5 Computational Biology (CB): This track aims to study and analyze complex biological data through mathematical and computational techniques of advanced.

These developments in level of Bioinformatics required many countries to develop a new model of curriculum that is taught in many universities, and which form a great challenge for most departments. Challenges and competition posed between developing countries focused on the launch of a mechanism for application of Bioinformatics in many universities through a powerful model is designed to provide quality education, and training students to use Bioinformatics tools. Here comes the important question of how to teach Bioinformatics for computational science students in the future and how to deliver the application of biology on a computer skill remains an unsolved educational riddle [14].

\section{Materials and Methods}

The results in this article depend on quantitative and qualitative data that collected from different sources such as websites or articles. The data has been collected based on conceptual framework (Figure 1) which considers the sample of 5 Universities for undergraduate and 5 universities for graduate level programs in Pakistan. These Universities are 
listed in (Table 1\&2). Similar sample of 5 universities offering undergraduate programs and 5 universities offering graduate programs was considered for 6 other developed and developing countries to ensure quantitative comparison and analysis..

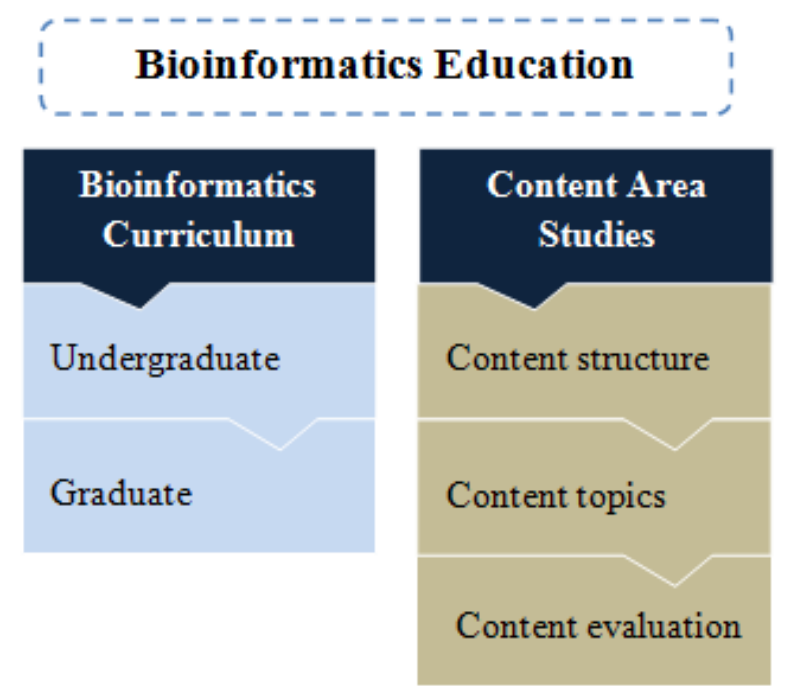

Figure 1. Conceptual framework for data collection and analysis

Bioinformatics Curriculum: courses that include undergraduate and graduate program of curriculum to ensure understanding and exemplary structure to students. And strive to provide adequate learning opportunities for discovery and connectivity, creativity, and building new knowledge through the face of a problem, and seek to solve them, in order to encourage students to request information independently.

Content Area Studies: contents provide students to master the skills, ideas, concepts, values, facts and structure to their education.

\section{Content Area Studies}

To develop a new multidisciplinary field of Bioinformatics curriculum in a country like Pakistan, as elsewhere, requires the promotion and sponsorship for undergraduate and graduate programs. A Bioinformatics curriculum model is based on strong multidisciplinary field in biological, statistical, mathematical and IT/ computer science (See Figure 2).

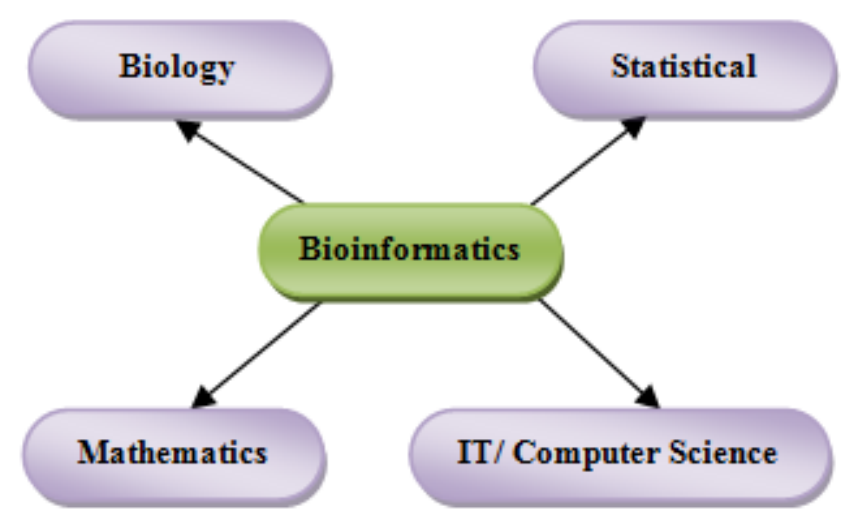

Figure 2. Major components of Bioinformatics curriculum

These components include most crucial subjects in Bioinformatics fields in developing curricula and address the needs of students coming from different backgrounds. Mixed composition of students showed in often to be effective, because they complement each other in the understanding of multiple disciplines and importance of Bioinformatics. Thus, Bioinformatics curriculum creates a spirit of challenge between developing countries to develop a strong framework to meet the requirements.

A comparison of various universities in developed and developing countries with selected Pakistani universities offering undergraduate and graduate degree at different levels is aimed at clarifying the importance and skills of Bioinformatics education. With variations in the course contents, this requires the introduction of amendments in current curriculum to accommodate future developments.

\section{Results and Discussions}

Comparison of subjects among undergraduate courses: There are currently five universities were selected from seven countries offering Bioinformatics courses for the bachelor's degree as listed in Table 1. The curricula of the five degrees of each country were examined from the websites. 
Table 1. Undergraduate Bioinformatics degrees and streams of selected countries

\begin{tabular}{|c|c|}
\hline \multicolumn{2}{|r|}{ 1. Pakistan } \\
\hline Baqai Medical University & http://www.baqai.edu.pk/BiitPrograms.aspx \\
\hline Mohammad Ali Jinnah University & https://www.jinnah.edu.pk/academics/course_list/of/BS+Bioinformatics \\
\hline $\begin{array}{l}\text { COMSATS Institute of Information } \\
\text { Technology }\end{array}$ & $\begin{array}{c}\text { http://ww3.comsats.edu.pk/CourseCatalogue2012/CourseCataloguedetails/ListofPrograms.aspx?Pid=1 } \\
\text { 4\&Sid=2\&Department=Biosciences\&Session=2011-2012 }\end{array}$ \\
\hline Government College University & http://gcuf.edu.pk/faculties/science/bio-informatics/bs-hons-bioinformatics/ \\
\hline International Islamic University & http://www.iiu.edu.pk/index.php?page_id=10930 \\
\hline \multicolumn{2}{|r|}{ 2. India } \\
\hline $\begin{array}{c}\text { Jaypee University of Information } \\
\text { Technology }\end{array}$ & http://www.juit.ac.in/attachments/FinalSyllabus.pdf \\
\hline Karunya University & http://www.karunya.edu.in/bioinformatics/academics/btechc.pdf \\
\hline D.Y.Patil University & http://www.dypatil.in/picrepimage/DBB_Programsoffered-BioinformaticsB.Tech_Bioinformatics.pdf \\
\hline SRM University & http://www.srmuniv.ac.in/sites/default/files/files/btech_syll_bie_r2013-14.pdf \\
\hline Amity University & \\
\hline \multicolumn{2}{|r|}{$\begin{array}{l}\text { http://www.amity.edu/aib/A05042.asp } \\
\text { Australia }\end{array}$} \\
\hline Murdoch University & http://handbook.murdoch.edu.au/units/details/?unit=BIO378\&year=2015 \\
\hline Flinders University & http://www.flinders.edu.au/courses/rules/undergrad/bsc/bsc-bion-ex.cfm \\
\hline University of Wollongong & http://www.uow.edu.au/handbook/yr2005/bcompbioinf.html \\
\hline University of New South Wales & http://www.engineering.unsw.edu.au/bioinformatics \\
\hline University of Western Australia & http://www.studyat.uwa.edu.au/_data/assets/pdf_file/0006/2385654/study_at_uwa-2008.pdf \\
\hline \multicolumn{2}{|r|}{ 4. Malaysia } \\
\hline UniversitiTeknologi Malaysia & http://www.ukm.my/jtlhe/pdf/4\%20JTLHE\%2017-\%20Dr\%20\%20Zeti\%20New.pdf \\
\hline Management and Science University & http://www.msu.edu.my/v9/faculty-health-life-sciences/bachelor-bioinformatics.php \\
\hline $\begin{array}{l}\text { INTI International University and } \\
\text { Colleges }\end{array}$ & http://newinti.edu.my/main/academic_programmes/american-university-programme/biosciences-2 \\
\hline Multimedia University & http://www.campusmalaysia.com/courses/computing-it/bachelor-science-hons-bio-informatics \\
\hline Universiti Selangor & http://fasbio.unisel.edu.my/bachelor-of-bioinformatics/ \\
\hline \multicolumn{2}{|r|}{ 5. Germany } \\
\hline Technical University of Munich & http://www.in.tum.de/en/for-prospective-students/bachelors-programs/bioinformatics.html \\
\hline Freie Universität & http://www.mi.fu-berlin.de/en/bioinf/stud/bachelor/index.html \\
\hline Saarland University & http://zbi-www.bioinf.uni-sb.de/en/information-potential-future-students/bachelors-study.html \\
\hline $\begin{array}{l}\text { University of Applied Sciences } \\
\text { Mittelhessen }\end{array}$ & http://www.thm.de/site/download/doc_download/748-bioninformatik-bachelor \\
\hline Bielefeld University & http://www.techfak.uni-bielefeld.de/en/bachelor-program-bioinformatics-and-genome-research-big \\
\hline \multicolumn{2}{|r|}{ 6. US } \\
\hline Rochester Institute of Technology & http://www.rit.edu/cos/lifesciences/pdf/BioinformaticsSchedu2131.pdf \\
\hline University of Pittsburgh & http://www.cs.pitt.edu/undergrad/bioinformatics/bsbi-major_req.php \\
\hline University of Nebraska & http://bioinformatics.ist.unomaha.edu/docs/BIOI\%20\%20Packet\%202009-2010.pdf \\
\hline Michigan Technological University & http://www.mtu.edu/biological/undergraduate/bioinformatics/ \\
\hline $\begin{array}{c}\text { California State University San } \\
\text { Bernardino } \\
\end{array}$ & http://bulletin.csusb.edu/colleges-schools-departments/natural-sciences/biology/bioinformatics-bs/ \\
\hline \multicolumn{2}{|r|}{ 7. Canada } \\
\hline University of Victoria & http://www.csc.uvic.ca/Program_Information/Undergraduate_Studies/BioinformaticsOption.htm \\
\hline University of Saskatchewan & http://www.cs.usask.ca/undergrad/programs/binfo.php \\
\hline University of Alberta & http://www.biology.ualberta.ca/programs/undergraduate/?Page=8508 \\
\hline University of Calgary & http://cumming.ucalgary.ca/bhsc/program/bioinformatics \\
\hline Lakehead University & http://bioinformatics.lakeheadu.ca/undergraduate-program/ \\
\hline
\end{tabular}


The major subjects in curriculum structure for the universities are classified into five major areas were chosen as a track for course content.

These areas were: Bioinformatics, biological sciences, IT/computer sciences, statistics and mathematics. Bioinformatics included all subjects that combined between computer science and biological science (e.g. Recombinant DNA, microarray analysis and proteomics). Computer sciences included programming subjects and other subjects. Biological sciences included all biology and chemistry subjects. Mathematics includes mathematical subjects. Statistics include all statistic and probability subjects. Each of the courses has some minor or elective subjects that fall in the other areas.

The comparison of subjects is distributed among undergraduate Bioinformatics a course within six areas is shown in (Figure 3). There were important variations in the average number of subjects representing these different countries, the subjects were selected from Bioinformatics courses which are offered by the selected universities.

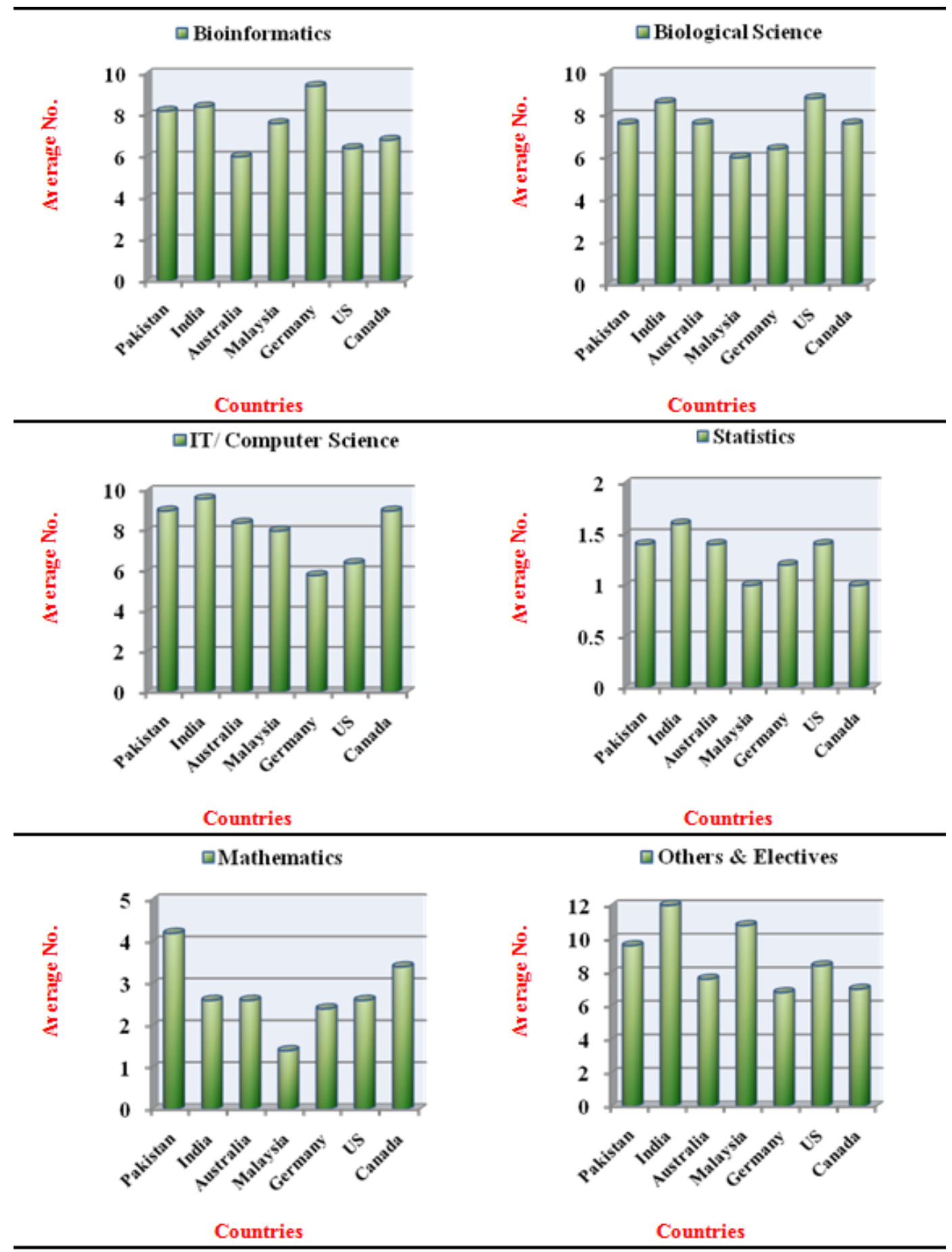

Figure 3. Distribution of subject areas covered in undergraduate Bioinformatics degrees 
Comparison of subjects among graduate courses: For graduate studies used the same way as used for the undergraduate studies based on selection of five universities from seven countries offering Bioinformatics courses for graduate degree are listed in (Table 2).

Table 2. Graduate Bioinformatics degrees and streams of selected countries

\begin{tabular}{|c|c|}
\hline \multicolumn{2}{|r|}{ 1. Pakistan } \\
\hline Virtual university of Pakistan & http://www.vu.edu.pk/AcademicPrograms/StudyScheme.aspx?sp=MS_in_Bioinformatics \\
\hline Quaid-a-Azam University & http://ncb.qau.edu.pk/index.php/programmes.html \\
\hline University of the Punjab & http://pu.edu.pk/program/description/5501\# \\
\hline CECOS University & http://www.hec.gov.pk/insidehec/divisions/aeca/curriculumrevision/documents/bioinformatics-2010.pdf \\
\hline University of Sindh & http://www.usindh.edu.pk/ \\
\hline \multicolumn{2}{|r|}{ India } \\
\hline $\begin{array}{l}\text { Institute of Bioinformatics and } \\
\text { Applied Biotechnology }\end{array}$ & http://www.ibab.ac.in/wp-content/uploads/2013/12/Syllabus_MSc-programme.pdf \\
\hline Pondicherry University & http://www.pondiuni.edu.in/sites/default/files/downloads/Bioinformatics2011-12-190413.pdf \\
\hline Savitribai Phule Pune University & http://www.unipune.ac.in/snc/bioinformatics_centre/bioinfo_webfiles/syllabus.htm \\
\hline $\begin{array}{l}\text { West Bengal University of } \\
\text { Technology }\end{array}$ & http://www.wbut.ac.in/page.php?id=255 \\
\hline Integral University & http://www.integraluniversity.ac.in/syllabus/MTechBioinformatics.pdf \\
\hline \multicolumn{2}{|r|}{ 3. Australia } \\
\hline Australian National University & http://programsandcourses.anu.edu.au/2015/specialisation/QBIL-SPEC \\
\hline University of Melbourne & https://graduate.science.unimelb.edu.au/master-of-science-bioinformatics \\
\hline Sydney University & http://sydney.edu.au/handbooks/archive/2011/science/postgraduate/coursework/bioinformatics.shtml \\
\hline University of Queensland & http://www.uq.edu.au/study/program_list.html?acad_prog=5541 \\
\hline La Trobe University & http://www.latrobe.edu.au/courses/feature/science-and-psychology/master-biotechnology-bioinformatics \\
\hline \multicolumn{2}{|r|}{ 4. Malaysia } \\
\hline University of Malaya & http://www.ips.um.edu.my/?modul=Programmes_Offered\&pilihan=Master_of_Bioinformatics \\
\hline Universiti Putra Malaysia & $\begin{array}{c}\text { http://www.hotcourses.com.my/study/course/malaysia/master-of-science-bioinformatics-and-system-biology } \\
\text {-research/52872596/program.html }\end{array}$ \\
\hline Perdana University & http://bioinfo.perdanauniversity.edu.my/pgdip/pgdip_brochure.pdf \\
\hline UniversitiTunku Abdul Rahman & $\begin{array}{l}\text { http://www.hotcoursesabroad.com/india/course/malaysia/master-of-science-computer-science-bio-informatic } \\
\text { s-research/55413858/program.html }\end{array}$ \\
\hline AIMST University & http://www.aimst.edu.my/faculties/applied_sciences/applied_sciences.php \\
\hline \multicolumn{2}{|r|}{ 5. Germany } \\
\hline Max Planck Gesellschaft & http://www.biochem.mpg.de/1819400/Bioinformatics-Core-Facility \\
\hline Ludwig Maximilian University & $\begin{array}{c}\text { http://www.uni-muenchen.de/studium/studienangebot/studiengaenge/studienfaecher/bioinform_/master/inde } \\
\text { x.html }\end{array}$ \\
\hline University of Giessen & http://www.uni-giessen.de/cms/study/courses/master/bioinformatics?set_language=en \\
\hline University of Freiburg & http://www.tf.uni-freiburg.de/studium/studiengaenge/master/studienplaene/bioinformatik2010_semester.pdf \\
\hline University of Bonn & http://www.b-it-center.de/Wob/en/view/class211_id1141.html \\
\hline \multicolumn{2}{|r|}{ 6. US } \\
\hline Rowan University & $\begin{array}{l}\text { http://rowanu.com/sites/default/files/documents/program-overviews/science-math/14-15/MS-Bioinformatics. } \\
\text { pdf }\end{array}$ \\
\hline Ohio University & http://www.ohio.edu/bioinformatics/programs.cfm \\
\hline George Mason University & http://masononline.gmu.edu/programs/bioinformaticsandcomputationalbiologyms/ \\
\hline Northeastern University & http://www.northeastern.edu/seattle/wp-content/uploads/2014/12/Bioinformatics-Slick-2014.pdf \\
\hline Boston University & http://www.bu.edu/bioinformatics/admissions/programs/md-track/ \\
\hline \multicolumn{2}{|r|}{ 7. Canada } \\
\hline Simon Fraser University & http://www.sfu.ca/bioinformatics/grad/courses.html \\
\hline Carleton University & http://calendar.carleton.ca/grad/gradprograms/bioinformatics/ \\
\hline University of Toronto & http://gbb.utoronto.ca/index.php/Category:Student_Members \\
\hline University of British Columbia & http://bioinformatics.bcgsc.ca/courses/index.html \\
\hline McGill University & http://www.mcgill.ca/mcb/academic/graduate \\
\hline
\end{tabular}


The comparison subjects are distributed among graduate Bioinformatics courses within six areas is shown in (Figure 4).The distribution based on total subjects that fall in the Bioinformatics, biological science, IT/ computer science, mathematical, statistical and elective or other subject in the course.
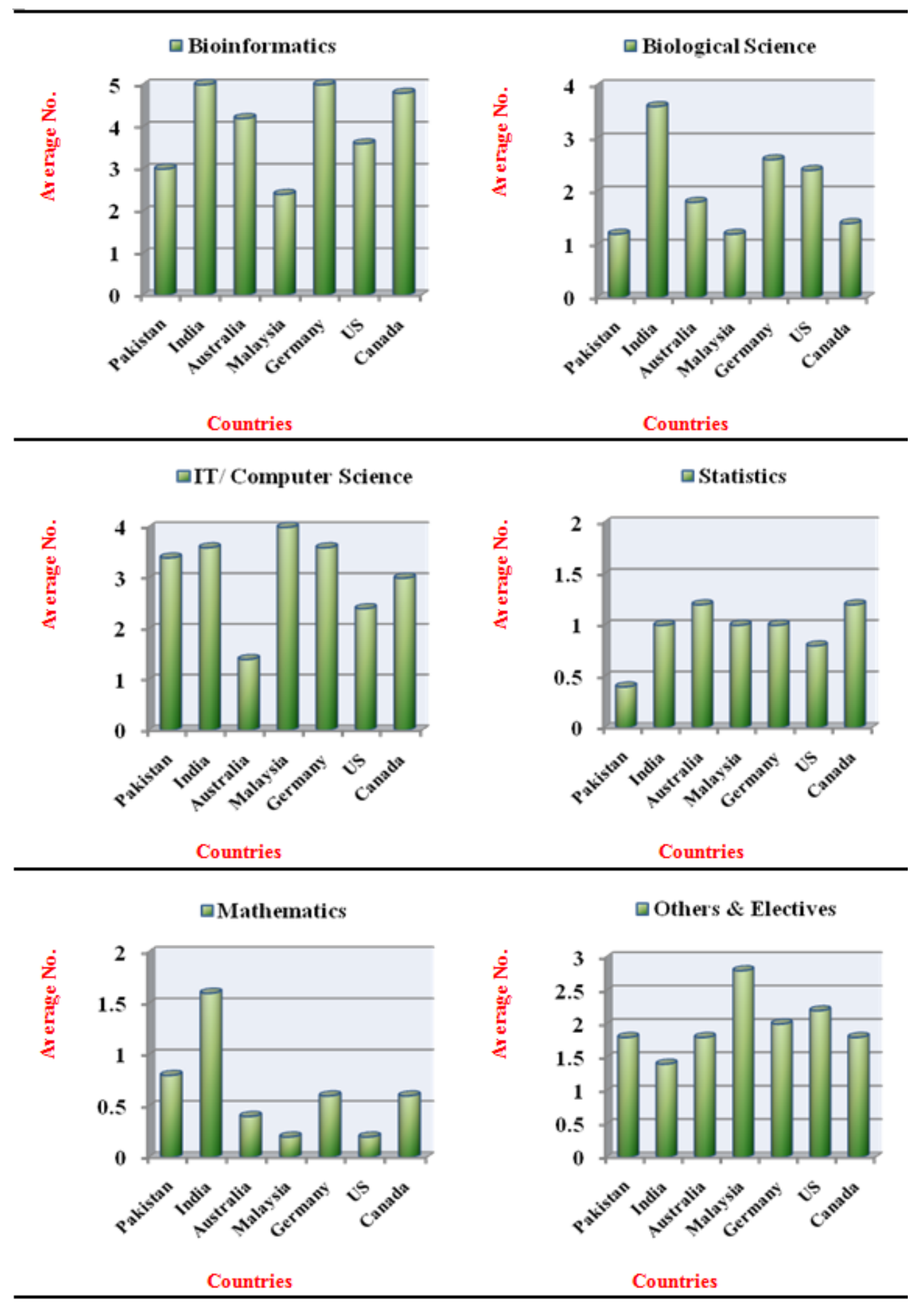

Figure 4. Distribution of subject areas covered in graduate Bioinformatics degrees

In this study, it is possible to make comparison through a number of various subjects that fall in major areas. This variation in the subjects means that some degrees are more skilled in producing Bioinformatics technicians. 


\section{Conclusions}

Through this study, some of the flagship initiatives related to Bioinformatics have been investigated in various countries and compared with the state-of-the-art standards of Bioinformatics education in Pakistan. Many nations around the world have taken initiatives for proper adoption and restructuring of Bioinformatics educational frameworks.

The crucial subjects in the Bioinformatics field fall in biology, mathematical, statistical and IT/ computer science. Therefore, the selected curricula depend on institute offering Bioinformatics degree, if the computer science institute offers Bioinformatics degree most subjects selected from the computer science side, but if the biology institute offers Bioinformatics degree most subjects from biology side, and so on. Different institutes have different curricula.

The contents of the undergraduate courses have more mathematics related subjects and as well as a number of overall subjects as compared to other developed countries. On the other side, the number of overall subjects in graduate courses is significantly less as compared to international counterparts. These ratios need to be balanced during future curriculum revision initiatives. The Bioinformatics courses in Pakistan emphasize on graduate programs more than undergraduate programs.

\section{Acknowledgements}

I would like to express my deepest appreciation to all those who provided me the possibility to complete this research article. A special gratitude I give to our authors, Dr. AZHAR ALI SHAH, Dr. ZAIN-UL-ABDIN KHUHRO and Dr. SHAHZAD AHMED MEMON, their contribution in stimulating suggestions and encouragement, helped me to coordinate my research article.

\section{REFERENCES}

[1] Altman, R. B. (1998), 'A curriculum for Bioinformatics: the time is ripe', Bioinformatics, 14(7), 549-550.
[2] Madhani, P. M. (2011), 'Indian Bioinformatics: Growth Opportunities and Challenges', PRERANA, Journal of Management Thought and Practice, 3(2), 7-17.

[3] Altman, R. B. (1998), 'Bioinformatics in support of molecular medicine', In Proceedings of the AMIA Symposium (p. 53). American Medical Informatics Association.

[4] Koch, I., \& Fuellen, G. (2008), 'A review of Bioinformatics education in Germany', Briefings in bioinformatics, 9(3), 232-242.

[5] Counsell, D. (2003), 'A review of Bioinformatics education in the UK', Briefings in Bioinformatics, 4(1), 7-21.

[6] Zatz, M. M. (2002), 'Bioinformatics training in the USA', Briefings in bioinformatics, 3(4), 353-360.

[7] Searls, D. B. (2012), 'An online Bioinformatics curriculum', PLoS computational biology, 8(9), e1002632.

[8] Cummings, M. P., \& Temple, G. G. (2010), 'Broader incorporation of Bioinformatics in education: opportunities and challenges', Briefings in Bioinformatics, 11(6), 537-543.

[9] Richard, R. J. A., \& Sriraam, N. (2005), 'A feasibility study of challenges and opportunities in computational biology: A Malaysian perspective', American Journal of Applied Sciences, 2(9), 1296.

[10] Ilyas, M., Sadique, S., Masood, K., Qamar, R. and Chohan, S.N. (2011). 'The development of computational biology in Pakistan: still a long way to go', PLoS Comput Biol, 7(6), p.e1001135.

[11] Higher Education Commission 2006, Islamabad, MS \& BS Bioinformatics program description. Available from: $<$ http://www.hec.gov.pk/InsideHEC/Divisions/AECA/Curric ulumRevision/Documents/Bioinformatics-2006.pdf>. [05 July 2006].

[12] Higher Education Commission 2010, Islamabad, MS \& BS Bioinformatics program description. Available from: $<$ http://www.hec.gov.pk/insidehec/divisions/aeca/curriculumr evision/documents/bioinformatics-2010.pdf>. [01 June 2010].

[13] Ragunath, P. K., Venkatesan, P., \& Ravimohan, R. (2009), 'New Curriculum Design Model for Bioinformatics Postgraduate program using Systems Biology Approach', J Comput Sci Syst Biol, 2, 300-305.

[14] Pevzner, P. A. (2004), 'educating biologists in the 21st century: Bioinformatics scientists vs. Bioinformatics technicians', Bioinformatics. 